\title{
Reservoir properties prediction using extended elastic impedance: the case of Nianga field of West African Congo basin
}

\author{
Charles Prisca Samba ${ }^{1} \cdot$ Hongmei $\mathrm{Lu}^{2} \cdot$ Habib Mukhtar ${ }^{2}$
}

Received: 15 September 2016/Accepted: 21 January 2017/Published online: 1 March 2017

(C) The Author(s) 2017. This article is published with open access at Springerlink.com

\begin{abstract}
Simultaneous seismic inversion and extended elastic impedance (EEI) were applied to obtain quantitative estimates of porosity, water saturation, and shale volume over Nianga field of Congo basin, West Africa. The optimum angle at which EEI log and the target petrophysical parameter give the maximum correlation was meticulously analyzed by additionally incorporating the concept of relative rock physics. Prestack seismic data were simultaneously inverted into $\mathrm{Vp}$, acoustic, and gradient impedances. The last two broadband inverted volumes were projected to Chi angles corresponding to the target petrophysical parameters, and three broadband EEI volumes were obtained. At well control points, the linear trends based on specific lithology between EEI and petrophysical parameters were then used to transform EEI volumes into quantitative porosity, water saturation, and shale volume cubes. In order to obtain the reservoir facies distribution, another concept of minimum energy angle was used to generate the background EEI cube, thereby enabling the mapping of reservoir facies. From quantitative porosity, water saturation, shale content, and background EEI cubes, favorable zones have been pinpointed which may suggest possible drilling locations for future development of the field.
\end{abstract}

Keywords Extended elastic impedance $\cdot$ Simultaneous inversion $\cdot$ Relative rock physics

Charles Prisca Samba

sambadebima@hotmail.com

1 Petroleum Exploration and Production Research Institute of Sinopec, Beijing, China

2 Faculty of Earth Resources, Key Laboratory of Tectonics and Petroleum Resources, China University of Geosciences, Wuhan 430074, Hubei, China

\section{Introduction}

Block 18 is situated in the southernmost portion of the lower Congo basin (Fig. 1)a Tertiary depocentre along the West African passive continental margin and is a product of Late Jurassic to Early Cretaceous rifting which heralded the first stage in the eventual opening of the southern Atlantic. Syn-rift sediments in the Lower Cretaceous (Neocomian-Barremian) are represented by the coarse siliciclastics, and the organic-rich lacustrine source deposits of the Bucomazi Formation, which lie unconformably on top of Pre-Cambrian fault blocks.

The Nianga field is located in deep water in the north central region of Block 18, approximately $175 \mathrm{~km}$ offshore to the northwest of Luanda, and is separated from the neighboring Mamba field to the immediate west by a structural saddle and a stratigraphic pinch out. It is the largest field within the block development area, with estimated recoverable reserves greater than $250 \mathrm{MMBO}$. It is a four-way dipping low-relief turtle structure, some $11 \mathrm{~km}$ long and up to $5 \mathrm{~km}$ wide. There are two Oligocene reservoir levels: aerially extensive but thin sheet sand-the Oligocene XB2, and a more complex stacked channel sequence-the Oligocene XB3; the XB3 is the most important in terms of recoverable reserves. The field was discovered in 1999, and an appraisal phase in 2001 involved the drilling of two exploration wells which confirmed a common OWC between the XB2 and the XB3 sands and the existence of a gas cap. A subsequent interference test proved that there was effective connectivity in the sands between the separate locations.

A robust inversion of petrophysical parameters and the distribution of the reservoir facies in 3D space are considered as key objectives for Nianga field development. The inversion of important petrophysical parameters such 


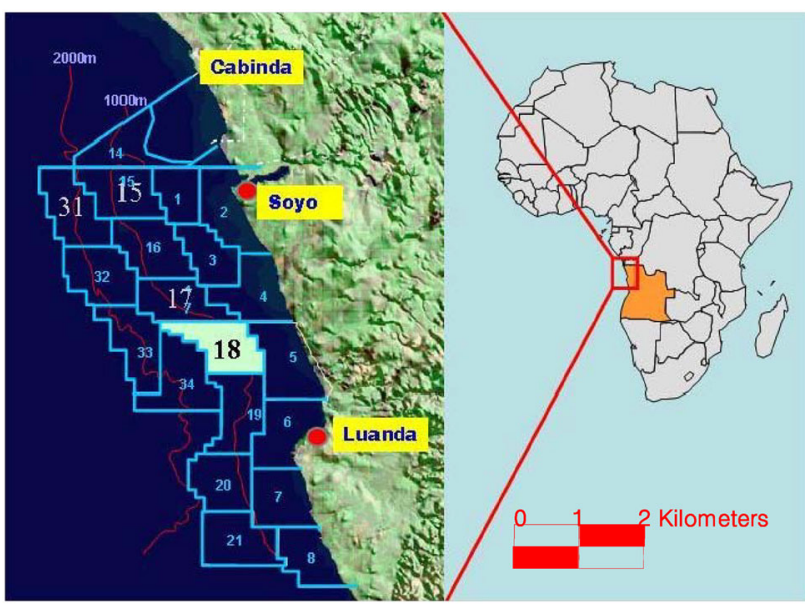

Fig. 1 Location of the study area in Block 18

as shale volume $\left(V_{\mathrm{sh}}\right)$, water saturation $\left(S_{w}\right)$, and porosity $(\phi)$ is of utmost importance mainly for three objectives: static geological model building, volumetric reserve estimation, and overall field development planning. There is a plethora of studies in the literature discussing the transformation of band-limited seismic data into reservoir properties. The commonly approach used to achieve those objectives consists of inverting deterministically seismic data into elastic parameters firstly, and then computing reservoir properties through statistical relationships derived at well control points between the petrophysical parameters $\left(\phi, S_{w}, V_{\mathrm{sh}}\right.$, etc.) and inverted P-elastic impedance (Dubucq and Van Riel 2001; Chatterjee et al. 2013; Vernik et al. 2002) or through rock physics templates Avseth et al. (2005). To deal with the ill-posed problem of deterministic inversion and also the presence of thin bed reservoirs, some authors prefer the stochastic inversion approach (Bachrach 2006; Doyen 2009; Sams et al. 2011; Sengupta and Bachrach 2007) and the nonlinear inversion approach (Morteza Amiri et al. 2015; Romero and Carter 2001).

In the complex stacked channel sequence-Oligocene XB3-discrimination of reservoir sand from the nonreservoir formations is an awkward exercise provided both lithologies show nearly the same values of acoustic impedance. In this study, considering the thickness of targeted reservoirs, largely above to the tuning thickness, deterministic seismic inversion coupled with extended elastic impedance (EEI) concept (Whitecombe et al. 2002) was applied on the Nianga field, in lower Congo basin. EEI concept is the improvement of the elastic impedance (EI) introduced by Connolly (1999), which breaks down the physical limit of the incidence angle range imposed by the two-term Aki-Richards approximations, allowing therefore arbitrary large positive or negative values of $\sin ^{2}(\theta)$ or $\tan \chi$. The breakthrough of Whitecombe is mainly based on findings by Dong (1996), which relate fundamental elastic parameters (bulk, shear moduli, and density) to AVO attributes (intercept, gradient, and curvature). As a result, in an intercept-gradient cross plot (reflectivity), at some $\chi$ (chi) angle projection, the reflectivity computed from Lamé parameters (shear modulus $\mu$, bulk modulus $\mathrm{K}$, and lambda $\lambda$ ) correlates with the tuned reflectivity. In addition, in an acoustic-gradient impedances cross plot, many different $\chi$ angle projections show high correlation between EEI and Lamé parameters. Depending on the quality of well log data, one can expect seeing a perfect correlation between the tuned reflectivity and reservoir properties such as porosity, clay content, and water saturation. It is worth stating that factors like depth trend (Ball et al. 2013, 2014; Thomas et al. 2013), compaction trend (Avseth et al. 2013) thickness, and lithology influence the quality of the correlation. Recently, Thomas et al. (2013) have recommended the use of the logarithm of EEI (ln EEI) instead of the full EEI during the correlation analysis between reservoir properties and EEI logs to avoid statistical biases and loss of parity with reflection.

We apply the concept of EEI to derive three petrophysical properties targeted at different reservoir units and to map the distribution of reservoir facies in 3D space. By determining optimal chi angles at which EEI is tuned to correspond to pseudo-petrophysical parameters and minimum background energy, inverted acoustic and gradient impedance cubes were used to estimate the corresponding EEI tuned cubes. At well control points, the linear trends shown by EEI versus petrophysical logs within a specific lithology were then used to transform EEI cubes into quantitative porosity, water saturation, and shale volume cubes. The first part of the paper discusses succinctly the theory behind EEI and simultaneous inversion, and the second and last parts tackle the methodology and the discussion of results, respectively.

\section{Background theory}

\section{Extended elastic impedance}

Whitecombe et al. expanded the concept of elastic impedance so that it can be used for fluid and lithology discrimination purpose. At the rotation angle $\chi$, EEI with normalization is defined as follows:

$\operatorname{EEI}(\chi)=V p_{0} \rho_{0}\left[\left(\frac{V p}{V p_{0}}\right)^{p}\left(\frac{V s}{V s_{0}}\right)^{q}\left(\frac{\rho}{\rho_{0}}\right)^{r}\right]$

where $\quad p=\cos \chi+\sin \chi, \quad q=-8 \mathrm{~K} \sin \chi, \quad$ and $r=\cos \chi-4 \mathrm{~K} \sin \chi$, and $V p_{0}, V s_{0}$ and $\rho_{0}$ are normalization factors of $V p$ (P-velocity), $V s$ (S-velocity), and $\rho$ (density), respectively. $\mathrm{K}$ is the average of $(V s / V p)^{2}$ over the entire $\log$ or the target reservoir depth interval. 
Obtaining EEI reflectivity volumes at $\chi=0^{\circ}$ and $\chi=90^{\circ}$ so that they can be transformed into acoustic and gradient impedances, respectively, was one of the reasons leading to the development of the EEI approach. Therefore, Eq. (1) can also be written as follows:

$E E I(\chi)=A I_{0}\left[\frac{A I}{A I_{0}}\right]^{\cos \chi}\left[\frac{G I}{A I_{0}}\right]^{\sin \chi}$

where $\mathrm{AI}_{0}$ is the normalization factor of $\mathrm{AI}$ (P-impedance) and GI is the gradient impedance.

Equation (2) can also be expressed in logarithm scale as

$\ln E E I(\chi)=\ln A I_{0}+\cos \chi \ln \left[\frac{A I}{A I_{0}}\right]+\sin \chi \ln \left[\frac{G I}{A I_{0}}\right]$

$\chi$ is considered as the rotational angle in the interceptgradient (AB) plane or ln GI-ln AI cross plot. It is related to the angle of incidence $\theta$ as follows:

$\tan \chi=\sin ^{2} \theta$

Equation (4) extends the range of measured data imposed by $\sin ^{2} \theta \quad\left(0<\sin ^{2} \theta \leq 1\right)$ to minus and plus infinities. By substituting Eq. (4) into the two-term Zoeppritz linearization equation, one obtains

$R \chi=A+B \tan \chi$

$A$ and $B$ are, respectively, the reflectivities of the intercept and gradient. If we assume at $\chi=\chi_{0}, R\left(\chi_{0}\right)=0$, one gets,

$\tan \chi_{0}=-\frac{A}{B}$

The minimum energy angle $\left(\chi_{0}\right)$ (Hicks and Francis 2006) is the angle at which reflectivity of the two-term AVO approximation is zero. The equivalent $\theta$ angle of $\chi_{0}$ is commonly beyond the range of recorded seismic, but if it happens to be within the recorded angle of seismic gather, one might expect to see a phase reversal of seismic reflection. Since the impedance contrast at the shale-shale interface is usually negligible at minimum energy, synthetic seismic obtained for this angle is referred to as background trend. This will definitely help to identify bodies highly contrasting within the background volume.

\section{Simultaneous inversion}

By convolving the AVO approximation equation of Wiggins et al. (1983) with wavelet $W(\theta)$, the synthetic seismic trace is written as follows:

$$
\begin{aligned}
S_{P P}(\theta)= & a / 2 W(\theta) \Delta \ln (A I)+b / 2 W(\theta) \Delta \delta \ln (G I) \\
& +c / 2 W(\theta) \Delta \delta \ln \left(V_{p}\right)
\end{aligned}
$$

where $a=1+\alpha_{G I} b+\alpha_{V_{p}} c, b=\sin ^{2} \theta, c=\sin ^{2} \theta \tan ^{2} \theta$. $\alpha_{\mathrm{GI}}$ is the gradient coefficient of the linear equation GI (in $y$-axis) versus AI (in $x$-axis)

$\alpha_{V_{p}}$ is the gradient coefficient of the linear equation $V_{p}$ (in $y$-axis) versus $\mathrm{AI}$ (in $x$-axis)

$\delta \ln \left(V_{p}\right)$ is the deviation away from the linear equation

$V_{p}$ (in $y$-axis) versus AI (in $x$-axis)

$\delta \ln (\mathrm{GI})$ is the deviation away from the linear equation

$\mathrm{GI}$ (in $y$-axis) versus AI (in $x$-axis)

In the matrix form, Eq. (7) is written as follows:

$\left[\begin{array}{c}S_{p p}\left(\theta_{1}\right) \\ S_{p p}\left(\theta_{2}\right) \\ \vdots \\ S_{p p}\left(\theta_{N}\right)\end{array}\right]$
$\quad=\left[\begin{array}{ccc}\frac{a\left(\theta_{1}\right)}{2} W\left(\theta_{1}\right) D & \frac{b\left(\theta_{1}\right)}{2} W\left(\theta_{1}\right) D & \frac{c\left(\theta_{1}\right)}{2} W\left(\theta_{1}\right) D \\ \frac{a\left(\theta_{2}\right)}{2} W\left(\theta_{2}\right) D & \frac{b\left(\theta_{2}\right)}{2} W\left(\theta_{2}\right) D & \frac{c\left(\theta_{2}\right)}{2} W\left(\theta_{2}\right) D \\ \vdots & \vdots & \vdots \\ \frac{a\left(\theta_{N}\right)}{2} W\left(\theta_{N}\right) D & \frac{b\left(\theta_{N}\right)}{2} W\left(\theta_{N}\right) D & \frac{c\left(\theta_{N}\right)}{2} W\left(\theta_{N}\right) D\end{array}\right]\left[\begin{array}{c}\ln (A I) \\ \delta \ln (G I) \\ \delta \ln \left(V_{p}\right)\end{array}\right]$

The diagonal matrix $\mathrm{D}$ is composed of the difference operation $\Delta$ as in (Hampson et al. 2005) and applied to each $\ln (\mathrm{AI}), \delta \ln \left(V_{P}\right)$ and $\delta \ln (\mathrm{GI})$.

The last column vector composed of $\ln (\mathrm{AI}), \delta \ln \left(V_{P}\right)$ and $\delta \ln (\mathrm{GI})$ is also represented by $\ln (Z) . W\left(\theta_{1 . . N}\right)$ is a banded matrix composed of extracted wavelets per partial angle stack. $S_{P P}\left(\theta_{1 . . N}\right)$ is a column vector of the near-, mid-, and far-seismic traces.

To solve Eq. (8) for $\ln (\mathrm{Z})$, i.e., $\ln (\mathrm{AI}), \delta \ln \left(V_{P}\right)$ and $\delta \ln (\mathrm{GI})$, the following total objective function is minimized:

$S_{\text {real }}-X \cdot \ln (Z)^{2}+\mu \ln (Z)-\ln \left(Z_{0}\right)^{2}$

where $\mu$ is the model weight, it has to be small to guarantee the inversion driven by real seismic data.

$\mathrm{Z}_{0}$ is the initial model with which the inversion starts.

The conjugate gradient method is used to iteratively modify $\ln (Z)$ until the difference between the synthetic seismic data $S_{p p}(\theta)$ and real seismic data $S_{\text {real }}(\theta)$ is minimized for near-, mid-, and far-stack angles. It is then straightforward to derive $Z$ by exponentiation of $\ln (Z)$.

\section{Methodology}

The proposed methodology aims at estimating tuned EEI cubes which approximately correspond to minimum background energy and petrophysical parameters such as porosity, water saturation, and shale volume cubes. 
Figure 2 shows the workflow of the methodology used in this study. It starts from (1) well log quality control (QC) and conditioning to ensure that the required data are available and physically reasonable in support of petrophysics and rock physics activities; (2) computation of EEI logs for different $\chi$ angles using Eq. (1) or Eq. (2) and the determination of the optimum angle that gives the best correlation (positive or negative) between EEI with the petrophysical target logs (porosity, shale volume, and water saturation); (3) QC, conditioning and simultaneous inversion of prestack time-migrated partial angle stacks such as near $\left(5^{\circ}-18^{\circ}\right)$, mid $\left(18^{\circ}-31^{\circ}\right)$, and far $\left(31^{\circ}-45^{\circ}\right)$ into $\mathrm{P}$-wave velocity, acoustic, and gradient impedances; (4) computation of equivalent EEI volume through Eq. (3) by using optimal angles; and (5) transformation of EEI volumes into quantitative petrophysical properties.

Reservoir facies distribution can be captured through the concept of minimum energy angle (Eq. 6). The easiest approach to determine this angle is to compute the EEI log spectrum with $\chi$ ranging from $-90^{\circ}$ to $+90^{\circ}$ (with an increment angle of 1).The determination of minimum energy angle $\chi_{0}$ is a visual process by analyzing the entire log spectrum in order to pinpoint zones where anomalies are better characterized. Once the angle $\chi_{0}$ is determined, step 4 is then applied to generate equivalent EEI volume.

\section{Result and discussion}

\section{Data gathering and quality check}

This step ensures that the required data are available in support of petrophysics and rock physics activities; it deals with improving well data which involve gaps correction and other unavoidable problems with gathered data. It also accounts for up-scaling when the need arises. The stage is an intensely visual process, requiring visualization tools and interactive manipulation widgets to make the process smooth, easy, and accurate.

All succeeding steps in the workflow depend on the quality and veracity of this step in the process. In this research, the measured $V p$ and $V s$ logs were of good quality, as shown in Fig. 3. In Fig. 3a, the red lines representing constant $V p / V s$ ratio showed that the values of both $V p$ and $V s$ are in a physically reasonable range. In addition, $V s$ log was also assessed by comparing measured versus predicted logs, as shown in Fig. 3b, where the black curve represents the measured (original) log and the red curve is the Greenberg-Castagna predicted log. The evaluation of multi-well depth trend plots (Fig. 3b) revealed that there were no spurious values for the velocity and density logs, as no circles points (each well is represented by different colors) deviated far away from the general trend. Elastic parameters such as acoustic impedance and
Fig. 2 Detailed workflow of the methodology

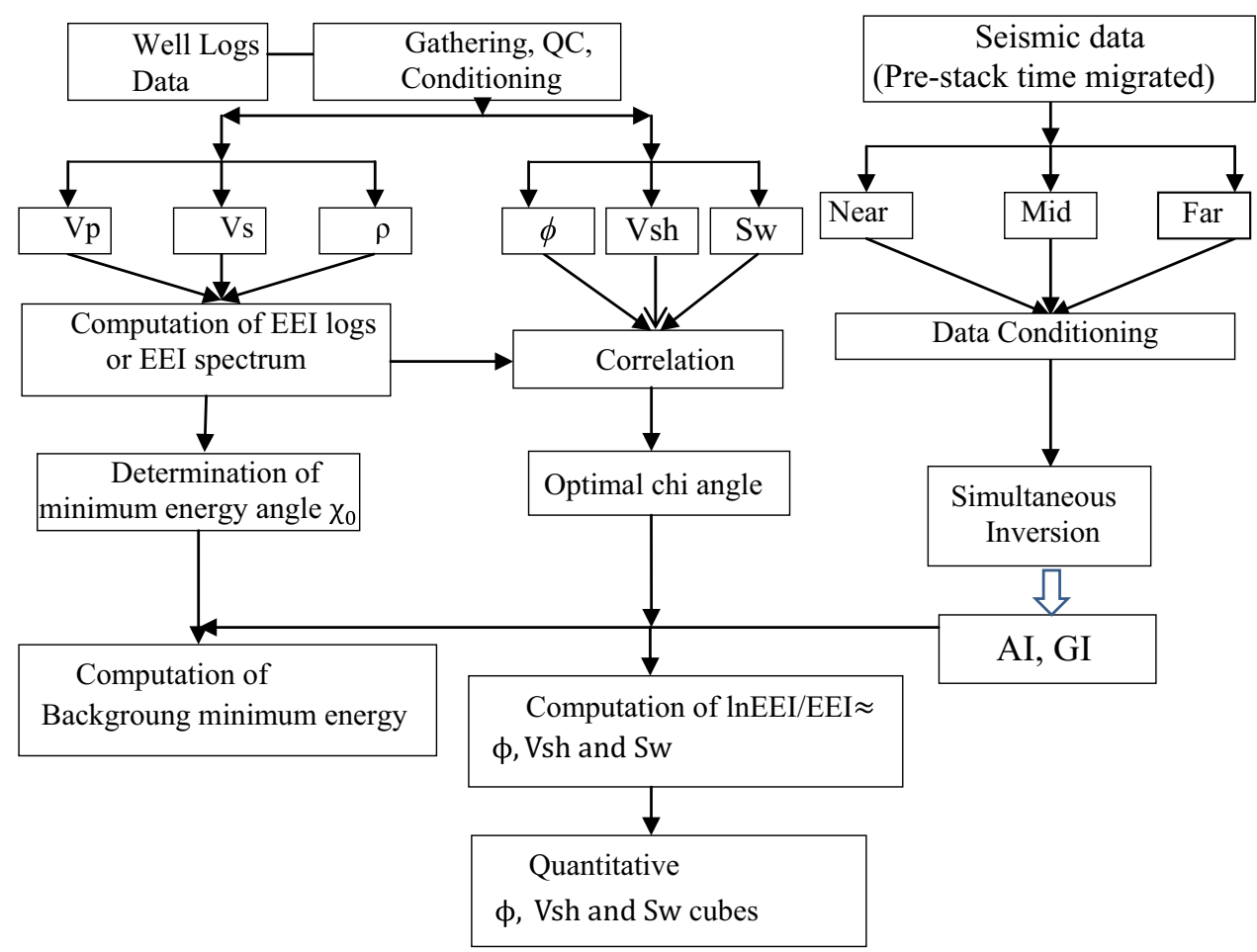



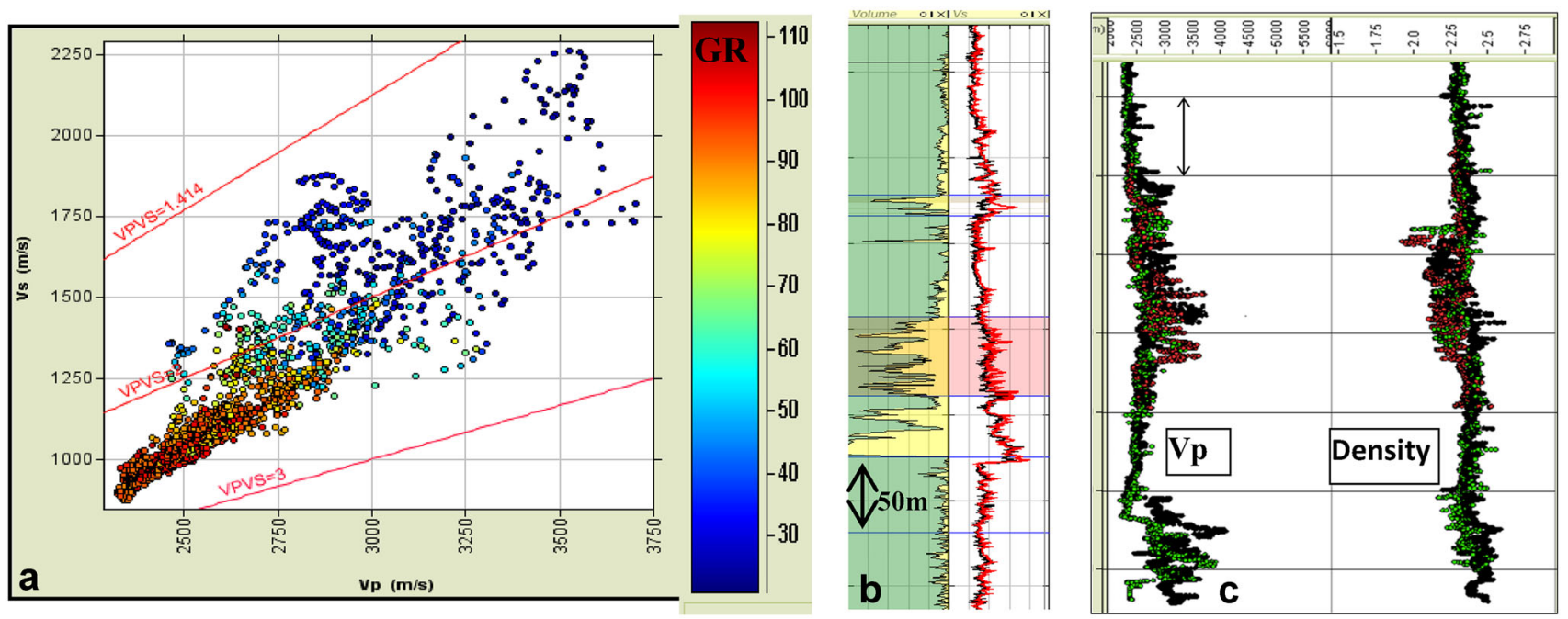

Fig. 3 a Cross plot of measured $P$ and $S$ velocities with the overlain red lines of constant $V p / V s$ ratio, b original (black and predicted (red) and b) the evaluation of multi-well trend plots

gradient impedance were then computed, and the value of $\mathrm{K}$ was computed by averaging values of $(V s / V p)^{2}$ in the target interval.

A lithology indicator (GR $\log$ ) was utilized to derive shale volume and clay content (C). This was done by linearly scaling GR to put forward a maximum and minimum $\mathrm{C}$ that corresponds to the $\mathrm{GR}$, in which $\mathrm{C}$ values of 0.07 for minimum GR (pure sand) and 0.93 for maximum GR (pure shale) were assumed. Total porosity $\log$ was calculated from the bulk density according to the mass balance equation (Mavko et al. 1998). Water saturation log was calculated from resistivity and porosity logs according to Archie's equation (Archie 1942).

\section{EEI angles computation and correlation}

Determining optimum angle for a particular target reservoir property $\log$ is the primary base to a successful implementation of the proposed technique herein. Hence, highquality wire line logs are needed for the computation of ln EEI as well as the correlation analysis. A set of EEI logs ranging from $\chi=-90^{\circ}$ to $\chi=+90^{\circ}$ was then computed by using Eq. (3). The normalization factors shown in the equation were obtained by averaging values of targeted $\log$ in the target interval.

Petrophysical logs such as porosity are generally trended, and the trends associated with $\ln$ EEI logs are function of the angle $\chi$. It is well documented that the unreal correlation coefficient may be the result of correlating two trended data (Ball et al. 2014). Prior to determine the optimum angle for a particular target petrophysical log, each single ln EEI and petrophysical target logs were decomposed into the trend background and the relative components, following proposed economics techniques as in Ball et al. (2014) and Hodrick and Prescott (1997). The correlation is then performed between two relative components. Doing so, the correlation coefficient can be improved. The red and black curves in panels 1 and 3 of Fig. 4 are the background trend and the original logs (ln $\operatorname{EEI}\left(74^{\circ}\right)$ ), respectively. Shale volume log is in panel 3 and $\ln \operatorname{EEI}\left(74^{\circ}\right) \log$ in panel 1 . The panels 2 and 4 show the de-trend curves of $\ln \operatorname{EEI}\left(74^{\circ}\right)$ and shale volume, respectively, i.e., after removing the background trend. Both initial $\ln \operatorname{EEI}\left(74^{\circ}\right)$ and shale volume $\operatorname{logs}$ were slightly trended.

There is an advantage of removing the background trend from the initial trended logs; hence, correlation of relative component (or de-trend curve) of ln EEI log and the targeted petrophysical log reveals a broad range of angles giving a maximum or minimum flat peak (Thomas et al. 2013).

Depending on the quality of the data, the correlation coefficient versus $\chi$ angles graph may show a maximum/ minimum peak or a plateau. In the case where the correlation coefficient versus $\chi$ angle plot shows a maximum or minimum plateau, one of the single values of the plateau or its center is considered to be optimal (Thomas et al. 2013).

The correlation between the target log and ln EEI logs for every $\chi$ angle was obtained. Maximum (positive) or minimum (negative) correlation was identified together with their corresponding angles; these identified angles are therefore considered to be optimal, thereby indicating how well a given petrophysical property can be predicted.

Three reservoir properties: porosity $(\phi)$, water saturation $\left(S_{w}\right)$, and shale volume $\left(V_{\mathrm{sh}}\right)$ show high correlation with ln EEI $\operatorname{logs}$ at $\chi=57^{\circ}, 39^{\circ}$, and $74^{\circ}$, respectively (Fig. 5a- 


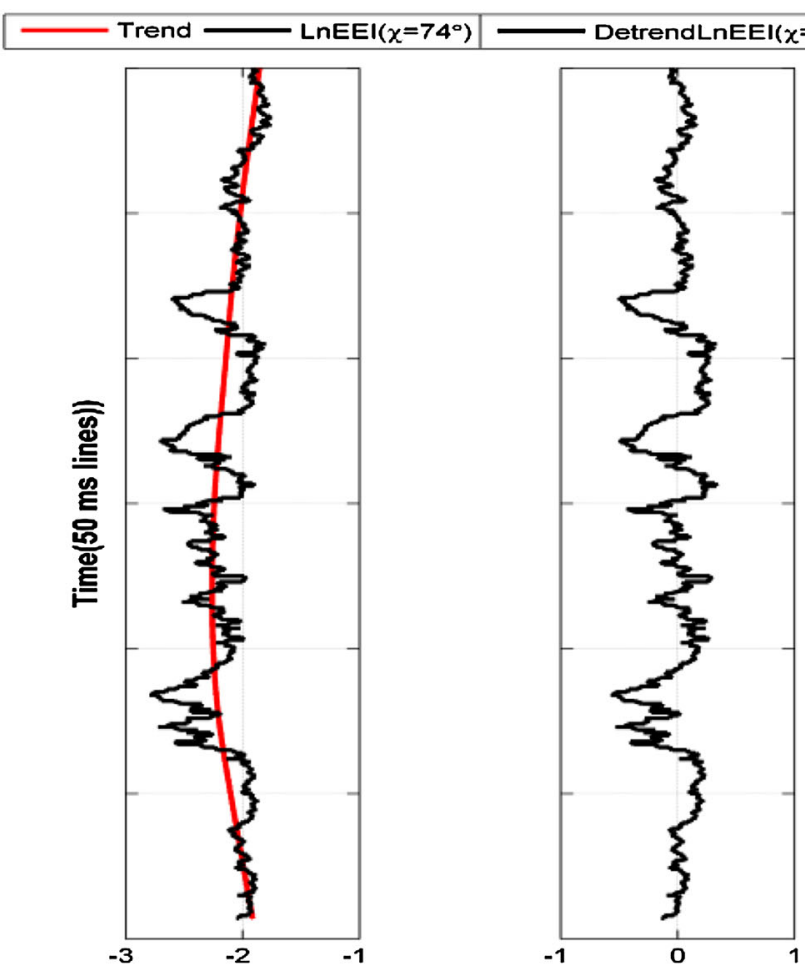

Fig. 4 Initial and de-trend logs. In the panel 1, the black and red curves are, respectively, the initial $\ln \operatorname{EEI}\left(74^{\circ}\right) \log$ and its trend component. Panel 2 shows the relative component of $\ln \operatorname{EEI}\left(74^{\circ}\right)$. In panel 3, black and red curves are, respectively, the initial shale

c). Even though some wells are not closely spaced, it has been observed that, for each well control points, EEI corresponding to $\chi=74^{\circ}$ or close to it gives a maximum correlation with the shale volume $(V \operatorname{sh} \log )$ at a correlation of $92 \%$, while ln EEI corresponding to $\chi=57^{\circ}$ or close to it gives a minimum correlation with the porosity $(\phi)$ at a correlation of $86 \%$, and $\ln$ EEI corresponding to $\chi=39^{\circ}$ or close to it gives a maximum correlation with the total water saturation $\log \left(S_{w}\right)$ at a correlation of $82 \%$. Porosity $\log$ gives a minimum correlation, that is, it correlates negatively with ln EEI (Fig. 5a). In this case, the results of EEI have to be negated in order to be able to make proper comparison with initial porosity log.

In order to validate result, ln EEI logs were then generated at the angles of maximum or minimum correlation, and compared to the corresponding petrophysical well logs as shown in Fig. 5d. A good match was observed between petrophysical parameters (in black) and the computed extended elastic impedance logs (in red).

\section{Seismic data QC and conditioning}

The overall quality of seismic partial stacks may suffer from time misalignment, side lobe wavelets, scaling of relative amplitude between near and far sections, especially
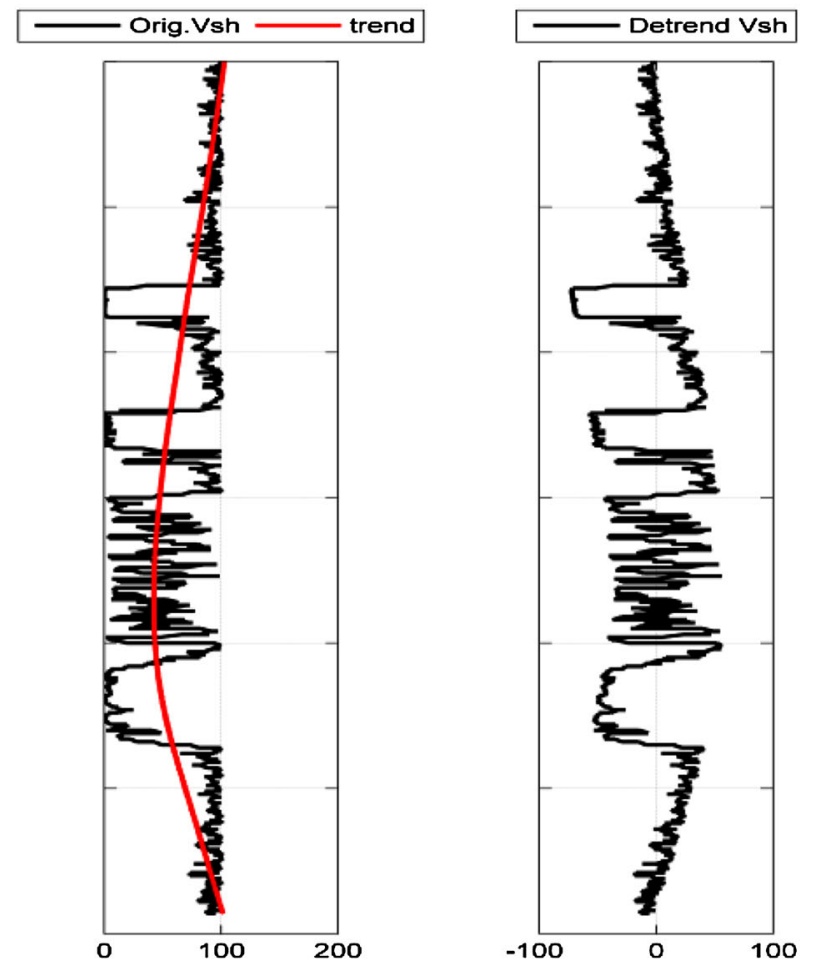

volume $\log$ and its smooth trend component. Panel 4 shows the relative component of shale volume log. The time distance between two lines on each panel is equal to $50 \mathrm{~ms}$

for deep targets reservoirs. The idea of conditioning seismic partial stacks consists of detecting and fixing potentials problems and thus preparing the seismic data for quantitative AVO studies. The different steps of conditioning the seismic partial stacks depend upon the results of the quality control (QC) and the knowledge of AVO end members gained through modeling.

The case of Nianga field presented herein, three partial stacks corresponding to the incidence angle ranges of 5-18 for near, 18-31 for mid, and 31-45 for far were available. Data were subjected to strict quality control, which did not reveal any severe problems. Synthetic seismograms of near and far sections depicted in Figs. 6 and 7 show that the actual data are zero phase. All the steps used during the QC process are outlined in Table 1.

\section{Simultaneous inversion of prestack time-migrated angle partial stacks}

Deterministic inversion is at its best when reservoir layering is relatively thick with high reflectivity. The data applied for this study were found to be suitable for deterministic inversion. The deterministic model applied herein is called simultaneous model-based inversion as described by Eqs. (7-9). In this type of inversion, an initial 
a Porosity, optimal $x$ angle $=57^{\circ}$ High corelation $=-0.87$

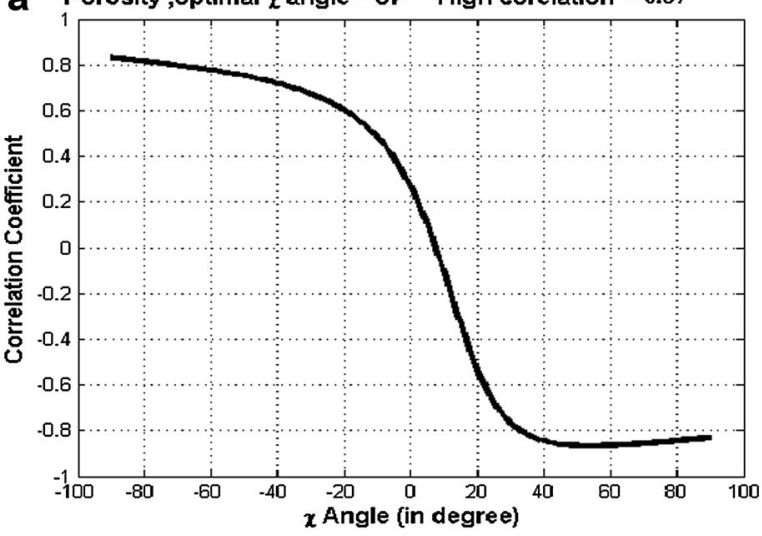

C

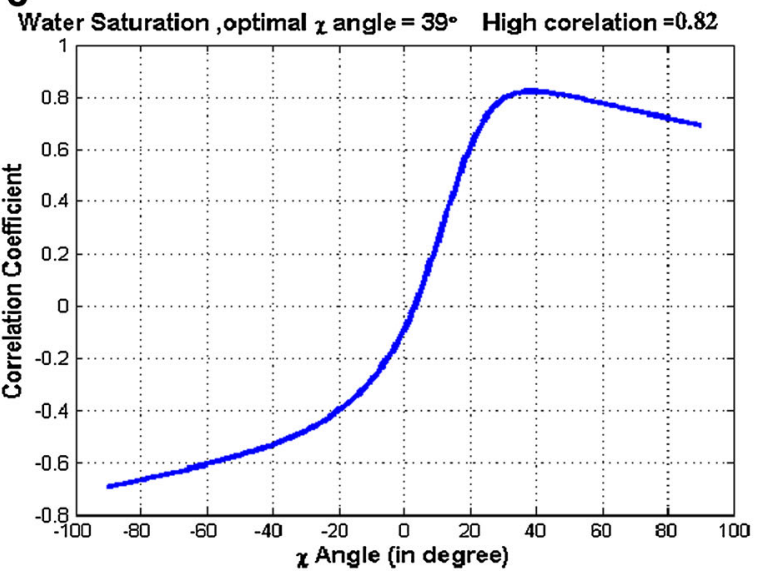

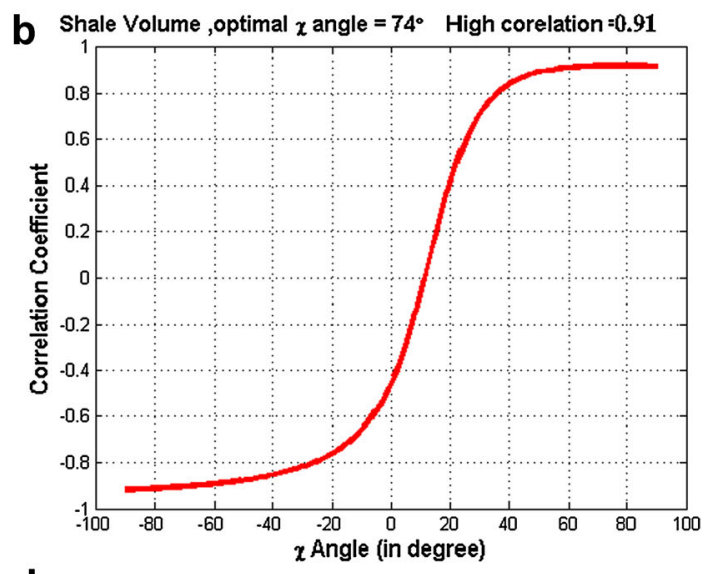

d

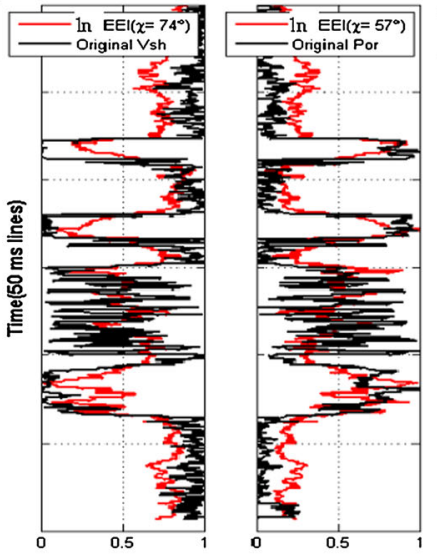

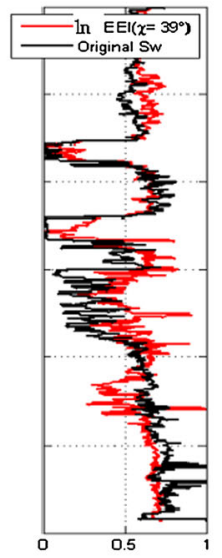

Fig. 5 Correlation of $\ln (\operatorname{EEI}(\chi))$ versus a $\ln$ (porosity), b $\ln ($ shale volume), and $\mathbf{c} \ln$ (water saturation). While $\mathbf{d}$ represents comparison of petrophysical logs with those from ln EEI using the optimum angles.
Original petrophysical logs are depicted in black while ln EEI (optimal angle) logs are in red. The time distance between two lines on each panel is equal to $50 \mathrm{~ms}$
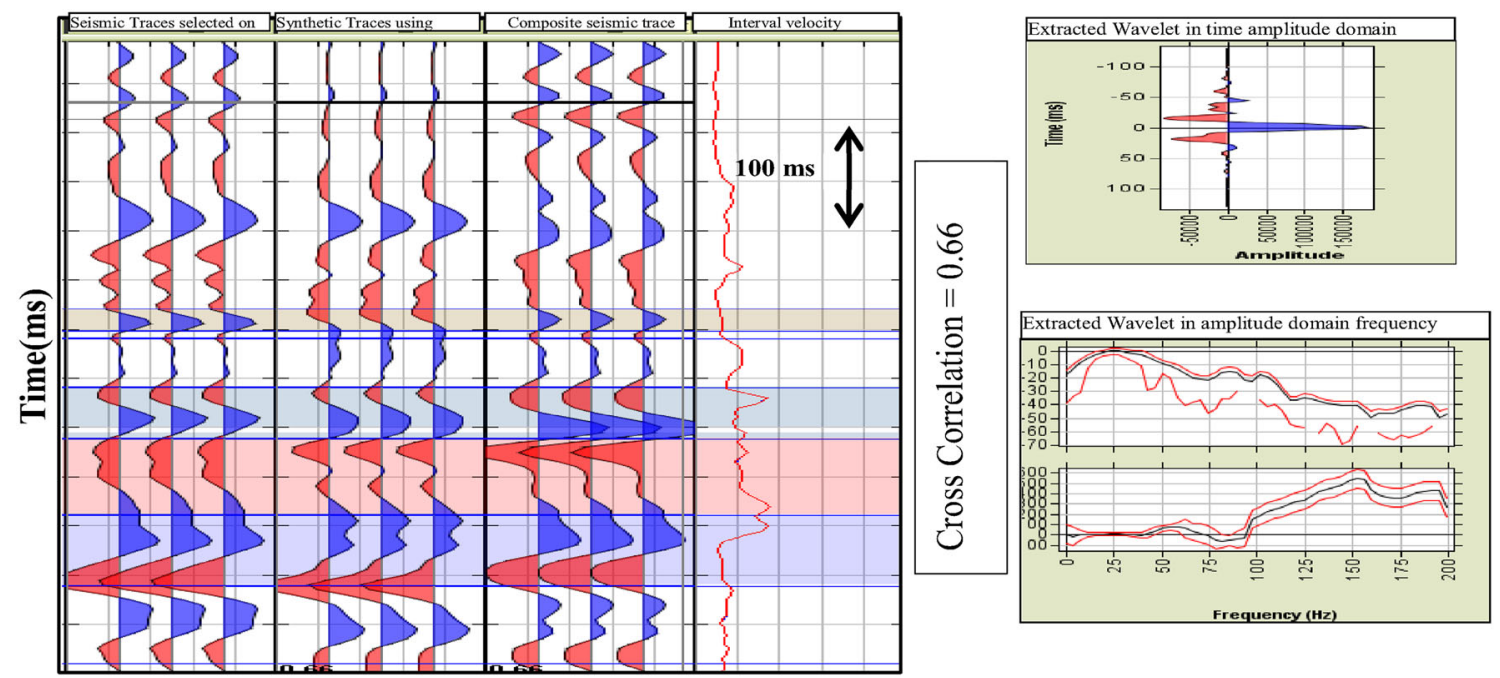

Fig. 6 Near-seismic well tie showing the extracted wavelet is zero phase. The left side shows selected seismic trace in panel 1, synthetic traces in panel 2, composite seismic trace in panel 3, and interval velocity in panel 4 . The right side shows, respectively, from top to the bottom the extracted wavelet in both time and frequency domains. (Mud-3 well) 

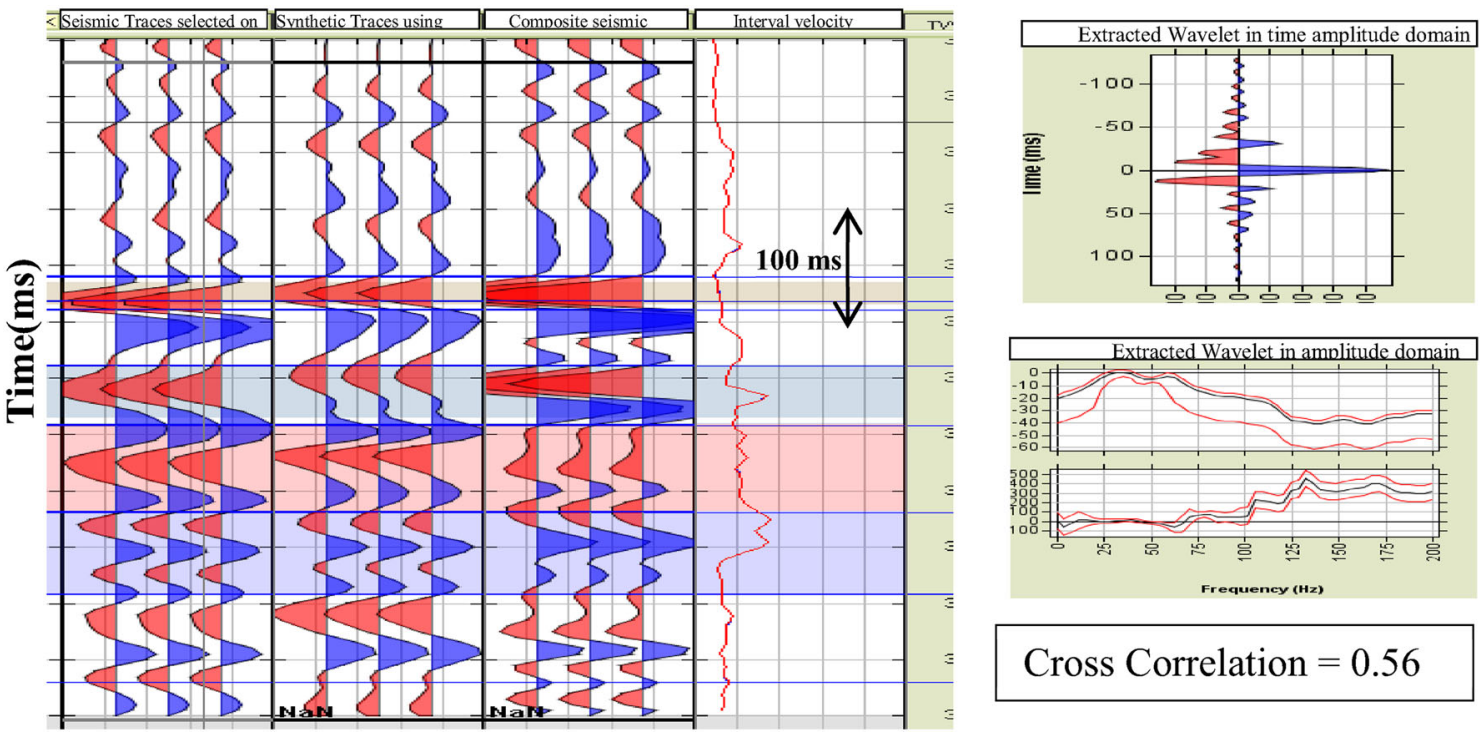

Cross Correlation $=0.56$

Fig. 7 Far-seismic well tie showing the extracted wavelet is zero phase. The left side shows selected seismic trace in panel 1 , synthetic traces in panel 2, composite seismic trace in panel 3, and interval velocity in panel 4 . The right side shows, respectively, from top to the bottom the extracted wavelet in both amplitude and frequency domains (Mud-3 well)

Table 1 Seismic data QC and conditioning

\begin{tabular}{lll}
\hline Step & Check/not check & QC results \\
\hline Zero-phase QC & Check & All three seismic cubes are zero phase (Figs. 5, 6) \\
Time shift QC & Check & Far section is time-shifted to about -6 ms (correction was applied) \\
Frequency and phase balancing & Check & Well balanced \\
\hline
\end{tabular}

impedance model is modified iteratively so as to make better its fit with seismic trace. With a good initial model, model-based inversion can be able to remove wavelet as well as turning effects.

\section{Low-frequency building}

In order to create a low-frequency model, a set of automatic horizons was generated, following the same procedure as Pauget et al. (2009).

Two control horizons, manually interpreted (Fig. 8a), were used to refine the generated automatic horizons so that they follow the stratigraphy accurately (Fig. 8b). Acoustic and gradient impedance logs from different wells were interpolated along the mapped horizons with accurate stratigraphic control, as shown in Fig. 8c (acoustic impedance). Finally, the interpolated model was filtered in the $0-10-\mathrm{Hz}$ low-frequency range (Fig. 8d). With respect to this study, the inverse distance-based algorithm was applied for the interpolation, and hence the detailed background models were obtained. A total of 4 wells were used to build three background models (AI, GI, and $V p$ ), from which the inversion started.

\section{Statistical/quantitative wavelet extraction and synthetic seismogram}

Prior to the inversion, near-, mid-, and far partial stacks were used to conduct seismic well tie. This is achieved by comparing the real and synthetic seismic data in the time window of interest (500 $\mathrm{ms}$ was used herein). The timedepth relationship at each well was available, which permitted an extraction of statistical wavelet in the target interval. The extracted statistical wavelet was then used to build a synthetic data. The correlation coefficient between the latter data and the real near seismic was improved from 0.4 to 0.5 by applying a wavelet phase rotation, and therefore the time-depth relationship was updated. Finally, the correlation coefficient was improved again up to 0.6 after using well data ( $V p, V s$, and density logs). The process consists of creating a reflectivity from $V p, V s$, and density logs using Zoeppritz equation or its approximations, convolving it with the previous rotated wavelet to generate the synthetic seismic traces, then the wavelet (especially the phase) and time-depth relationship is iteratively updated so that the synthetic seismic traces fit pretty well the real seismic data as shown in Figs. 6 and 7. 
a

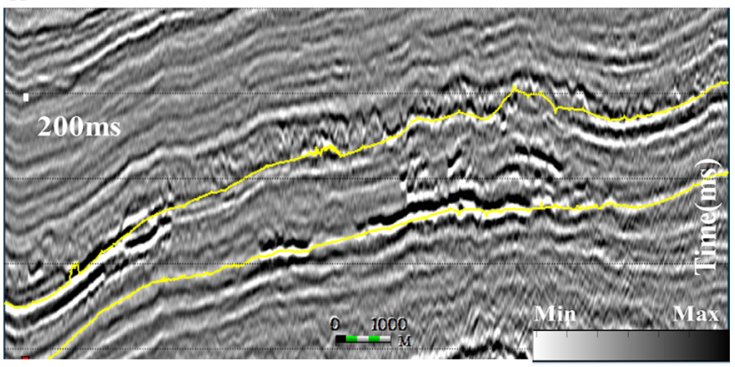

c

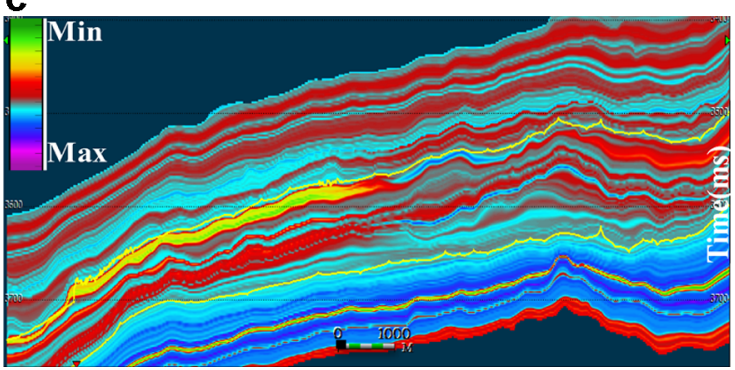

Fig. 8 Generation of low-frequency models used in the inversion: a control horizons delimiting the target and used to refine the generated automatic horizons, b numerous generated auto-tracked

Quality control on wavelets showed that it is stable up to the frequency of $55 \mathrm{~Hz}$, and the correlation coefficients are acceptable.

Once the edited time-depth relationship is produced for each well and the optimum seismic wavelets are extracted, it becomes then straightforward to invert seismic data. Three wells in the target area were used to constrain the inversion results by cross plotting $\ln \mathrm{AI}$ versus $\ln \mathrm{GI}$ in one hand, and $\ln \mathrm{AI}$ versus $\ln V p$ in the other hand. Linear trends obtained from those relationships were then used for the inversion regularization. b

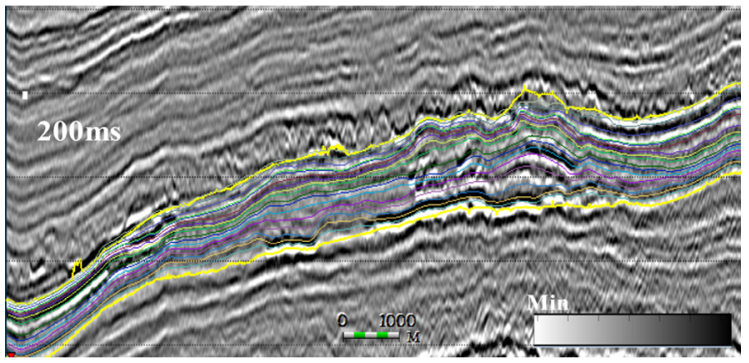

d

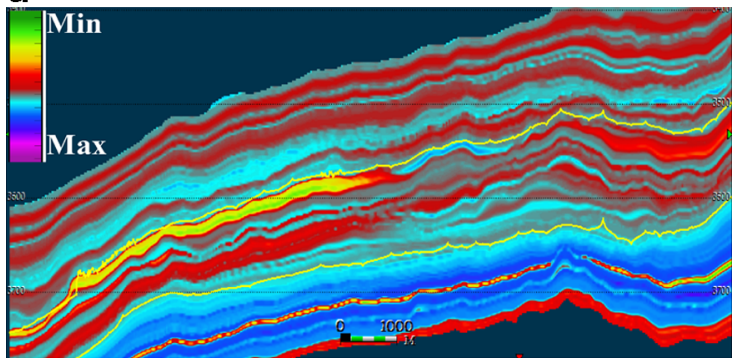

horizons following the stratigraphy, $\mathbf{c}$ interpolation of elastic properties along the auto-tracked horizons, $\mathbf{d}$ filtering and generation of low-frequency model

\section{Seismic inversion results and $Q C$}

Figure 9 shows the section view of acoustic and gradient impedance inversion results produced by this approach. The section passes through 3 wells depicted by gamma ray logs (black curve on each section). Mud-1 well was omitted in the inversion process to serve as a blind test well, and the rest wells were used to generate the low-frequency background model. Considering the 4 wells used in this study, including Mud-1 well (blind test well), the correlation coefficients between the inverted and the initial logs were
Fig. 9 Sections passing though wells showing the inverted acoustic impedance (a) and gradient impedance (b). The overlain black curves on the sections are GR logs
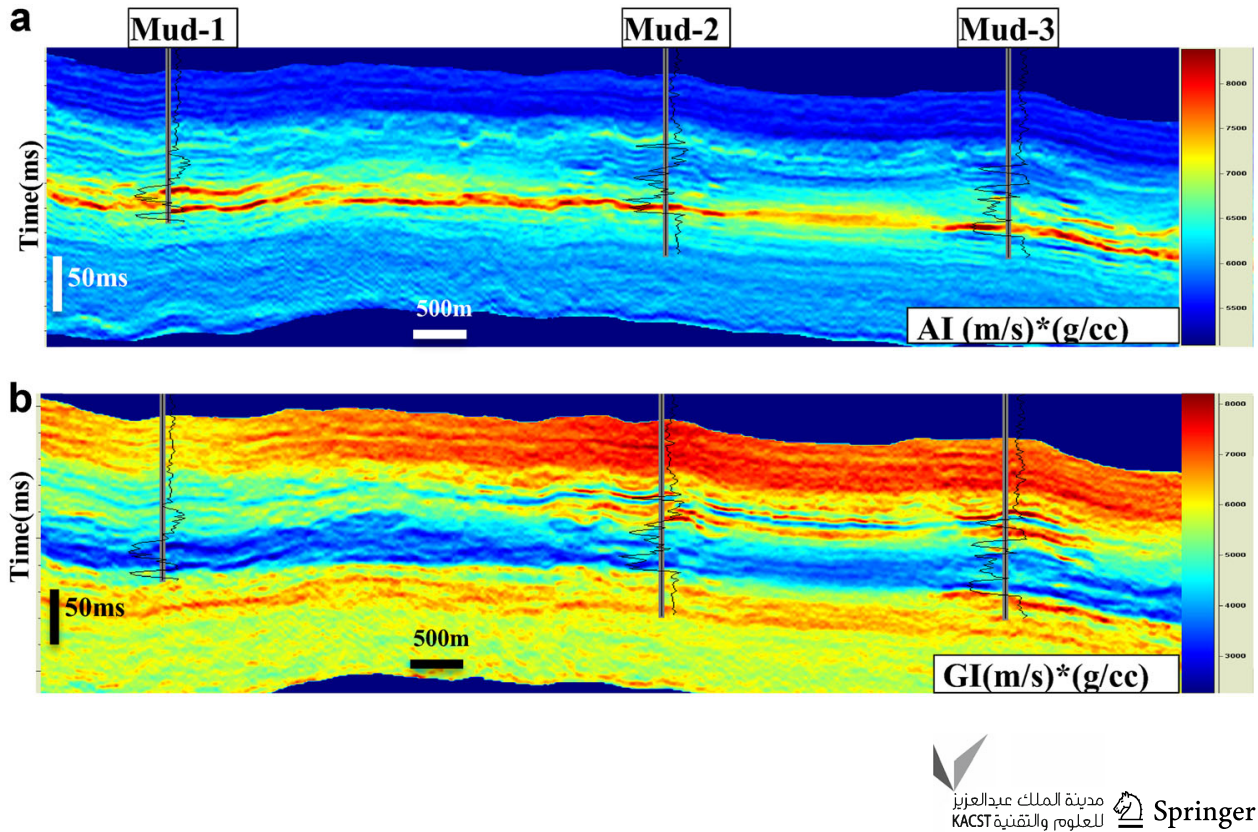
of 0.90 for acoustic impedance and 0.82 for gradient impedance (Fig. 10a, b). Figure 10c shows the inverted impedances (acoustic and gradient impedances in red color) with the initial well $\log$ measurements (in black color).

The high correlation factors shown in Fig. 10a, b and the acceptable inversion results at the blind well test revealed the acceptability of the inversion results.

\section{Computation of equivalent EEI volume}

The fact is that the inverted elastic properties match with the initial log measurements; both inverted impedances can be transformed into ln EEI volumes using Eq. (3). The optimal angles estimated in "EEI angles computation and correlation" section were used to compute the corresponding ln EEI. The target time interval bounding with two horizons (manually interpreted), as shown in Fig. 8a, was used to compute the normalization factor $\mathrm{AI}_{0}$.

Figure 11 presents $\ln$ EEI volumes corresponding to the optimal angles of $\chi=74^{\circ}, \chi=57^{\circ}$ and $\chi=39^{\circ}$ computed from Eq. (3).

The three sections passing though wells are extended elastic impedance at $\chi=57^{\circ}$ (Fig. 11a), corresponding to porosity volume, extended elastic impedance at $\chi=74^{\circ}$ (Fig. 11b), corresponding to shale content volume, and extended elastic impedance at $\chi=39^{\circ}$ (Fig. 11c), corresponding to water saturation volume. For comparison reasons, the initial $\ln$ EEI $\left(74^{\circ}\right)$ and $\ln$ EEI $\left(57^{\circ}\right) \operatorname{logs}$ are overlain on each section, and it can be clearly seen that the inverted volumes honor the original data perfectly. Gamma ray (GR) logs are intentionally displayed on the water saturation section (Fig. 11c), as it is easy to show low GR corresponding to sand reservoir. However, not all reservoirs are showing low values of $\mathrm{Sw}$, explaining evidently that some reservoirs are water-bearing (red rectangle in Fig. 11c).

From Fig. 11, it can be seen that it is easy to map the entire sand reservoirs which show low values for $\ln \operatorname{EEI}\left(\chi=74^{\circ}\right)$ and high values for $\ln \operatorname{EEI}\left(\chi=57^{\circ}\right)$, and above all the oil sand units which are represented by low values of $\ln$ EEI $\left(\alpha=39^{\circ}\right)$ can also be easily mapped. Therefore, it is straightforward to map the reservoir sands from those ln EEI-derived petrophysical properties.

\section{Transformation of EEI volume into quantitative petrophysical property}

By cross plotting EEI logs data in 3D space, color coded by porosity and shale volume, the linear trend-based lithologies were clearly seen. Therefore, the derived equations from those trends (especially the one shown by the sand
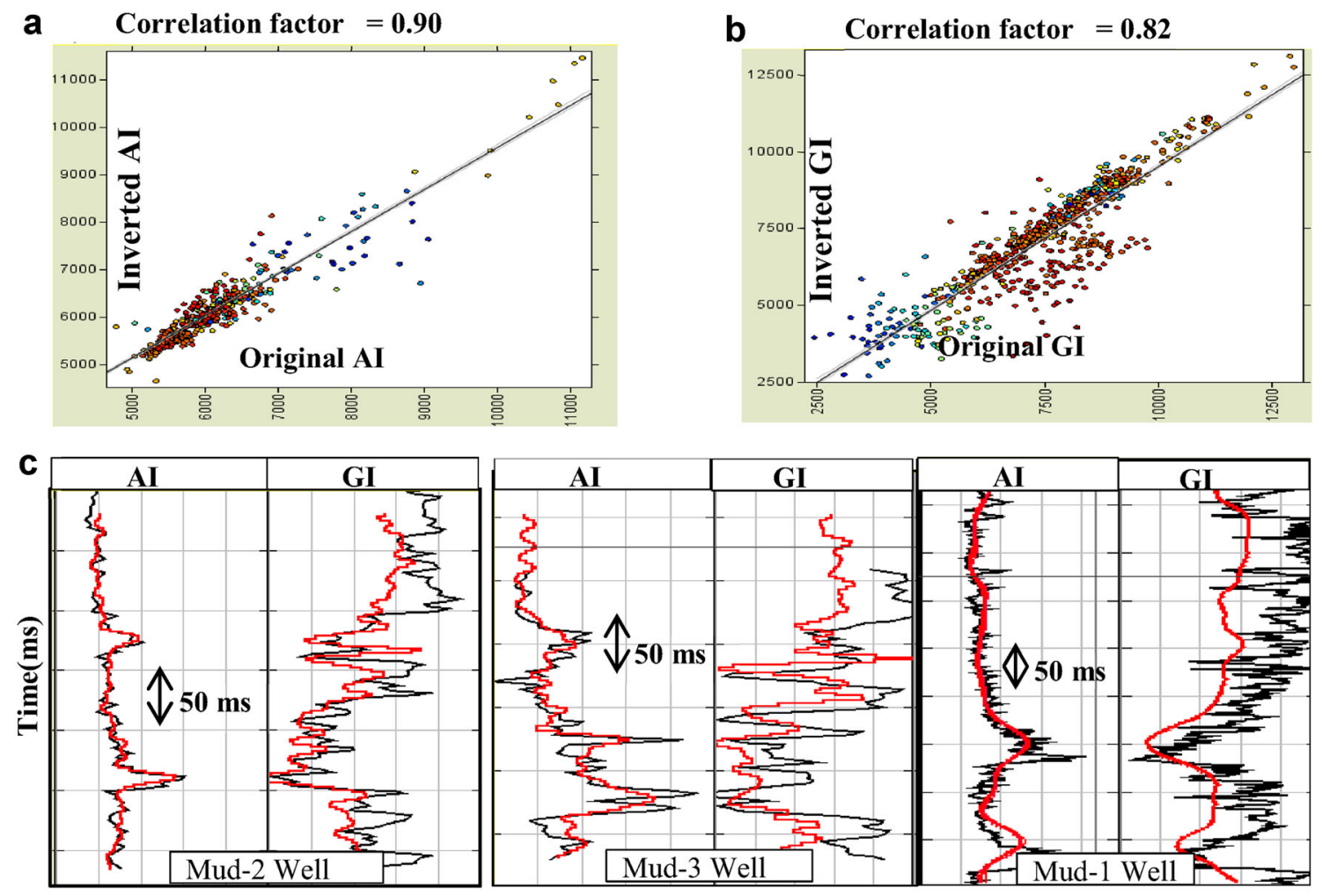

Fig. 10 QC of inversion results: inverted seismic impedances versus well log impedance: a cross plot of acoustic impedance, b cross plot of gradient impedance, $\mathbf{c}$ the inverted (red) and original logs (black) for three wells are displayed for comparison 
Fig. 11 ln EEI sections passing though wells showing a ln EEI at $\chi=57^{\circ}$, corresponding to porosity volume, and $\mathbf{b} \ln$ EEI at $\chi=74^{\circ}$, corresponding to shale content volume, and c $\ln$ EEI at $\chi=39^{\circ}$, corresponding to water saturation volume. Except the last figure, corresponding petrophysical properties derived from well logs are overlain on the two sections for comparison. GR logs are intentionally plot on the water saturation section, as it is easy to show low GR corresponds to sand reservoir. However, not all reservoirs are showing low values of $S_{w}$, explaining evidently that some reservoirs are water-bearing (red rectangle)
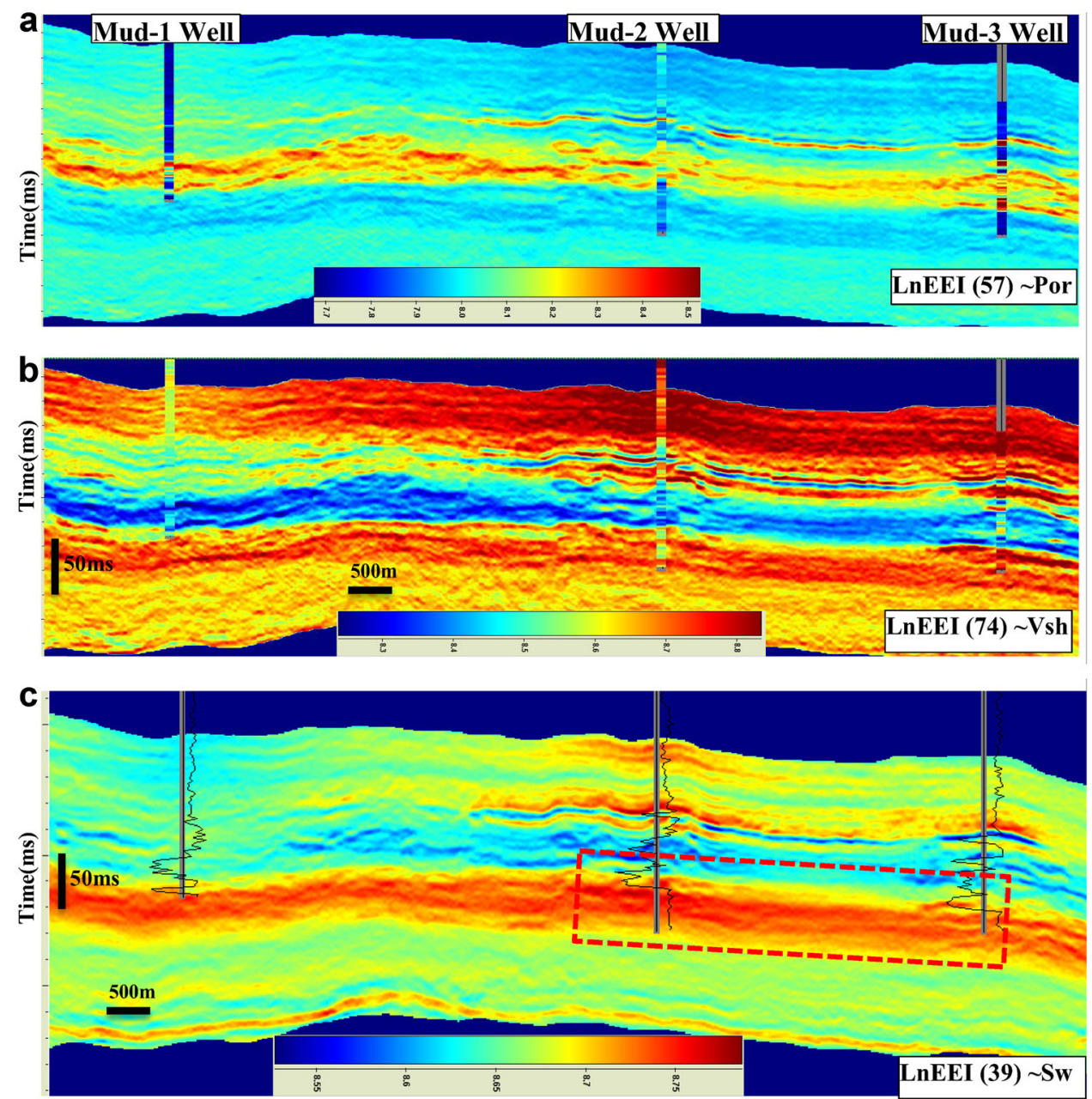

reservoir) were then used to convert the EEI volumes into shale content, water saturation, and porosity volumes. Figure 12a shows the RMS (root mean square) of porosity map of the top and bottom of XB3 unit. Figure 12b shows the RMS of shale content of the same unit. Zones where contour lines are inferior to $3640 \mathrm{~ms}$ with high porosity and lower shale content are favorable zones. The close observation of Fig. 12a, b reveals that the reservoir is clearly defined by shale volume. In addition, high values of porosity map which should be related to the presence of reservoir are also observable. In the east of the porosity map, there is a quite big zone with very high values, which geologically does not make sense to be a potential zone insofar as the zone is in the low relief; thus, it can be declared as a non-hydrocarbon potential zone.

\section{Facies distribution}

In order to obtain the reservoir facies distribution, the concept of minimum energy $\chi_{0}$ was applied on the entire formation. The idea was also to isolate the oil reservoir sand from the non-reservoir facies. After generating the EEI $\log$ spectrum (angle ranging from $\chi=-90^{\circ}$ to $\chi=+90^{\circ}$ ), the analysis of the spectrum was meticulously carried out and the minimum energy angle was located at exactly $\chi=22^{\circ}$, as shown in Fig. 13a. This conveys the information that at $\chi=22^{\circ}$, the non-reservoir beds (shale) contrast poorly with each other in the log property; thus, bodies highly contrasting within the background shale could be seen and captured easily. That is why this angle is considered as the minimum energy angle. The computed EEI at this angle is also called the background EEI (Hicks and Francis 2006).

A comparison between the background EEI with resistivity and P-Impedance logs is shown in Fig. 13b, which revealed that $\mathrm{P}$-impedance log could not discriminate the sand unit from the non-reservoir (green ellipse in Fig. 13b). Moreover, the separation between the two lithologies (shale for non-reservoir and sand for reservoir) is evident (Fig. 14). To capture the oil sand reservoir facies, the distribution of oil sand reservoir facies in background EEI section, as shown in Fig. 15, was analyzed at well control 

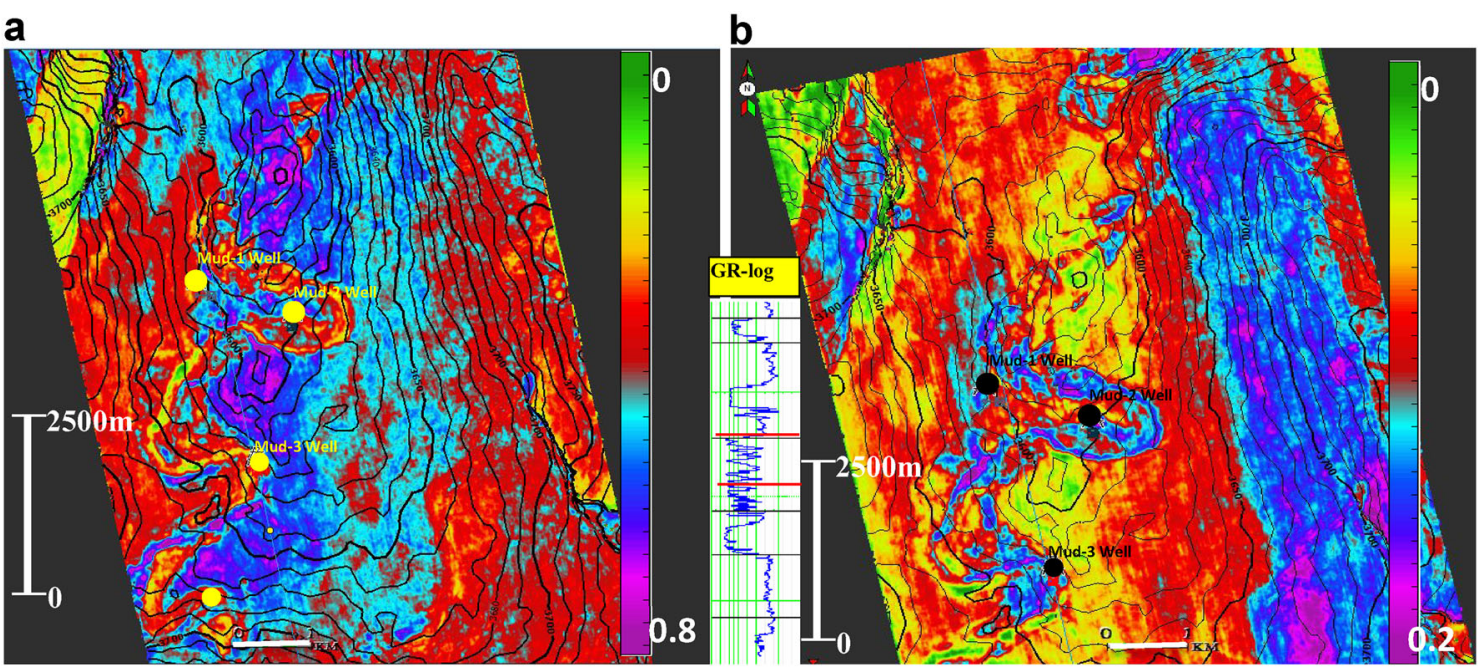

Fig. 12 RMS of XB3 unit (delimited by red lines on GR $\log$ ); a shale volume and $\mathbf{b}$ porosity volume. Zones where contour lines are inferior to $3640 \mathrm{~ms}$ with high porosity and lower shale content are considered as favorable zones

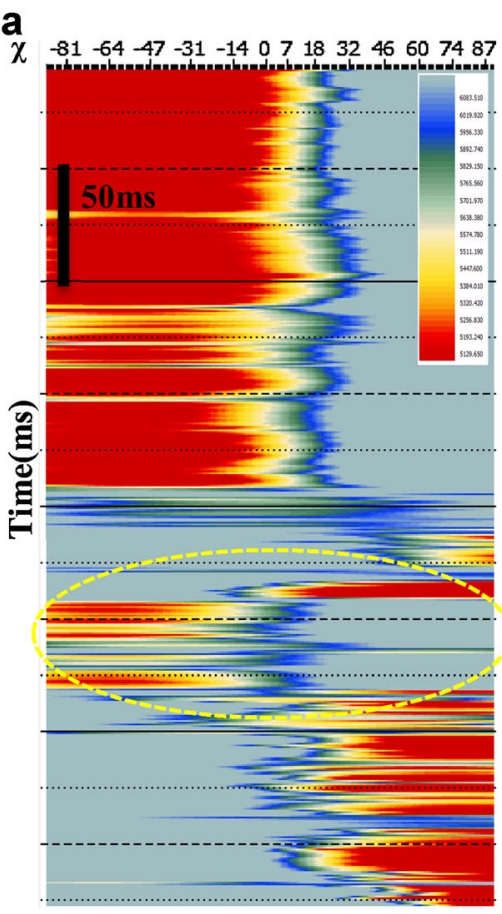

Fig. 13 a EEI log spectrum indicating the minimum energy $\chi$ at $22^{\circ}$ b comparison of EEI log at minimum energy angle of $\chi=22^{\circ}$ with P-impedance. The shale volume, $\operatorname{EEI}\left(74^{\circ}\right)$, and resistivity logs are also displayed, in order to facilitate the interpretation. The reservoir

points to determine the cutoff criteria from which the anomaly (oil sand reservoir facies) will be scanned. A voxel search technique is used for the scanning.

The black lateral line in Fig. 14 is a potential extension of oil water contact as interpreted from wells. In the reservoir unit, the background EEI captured accurately the

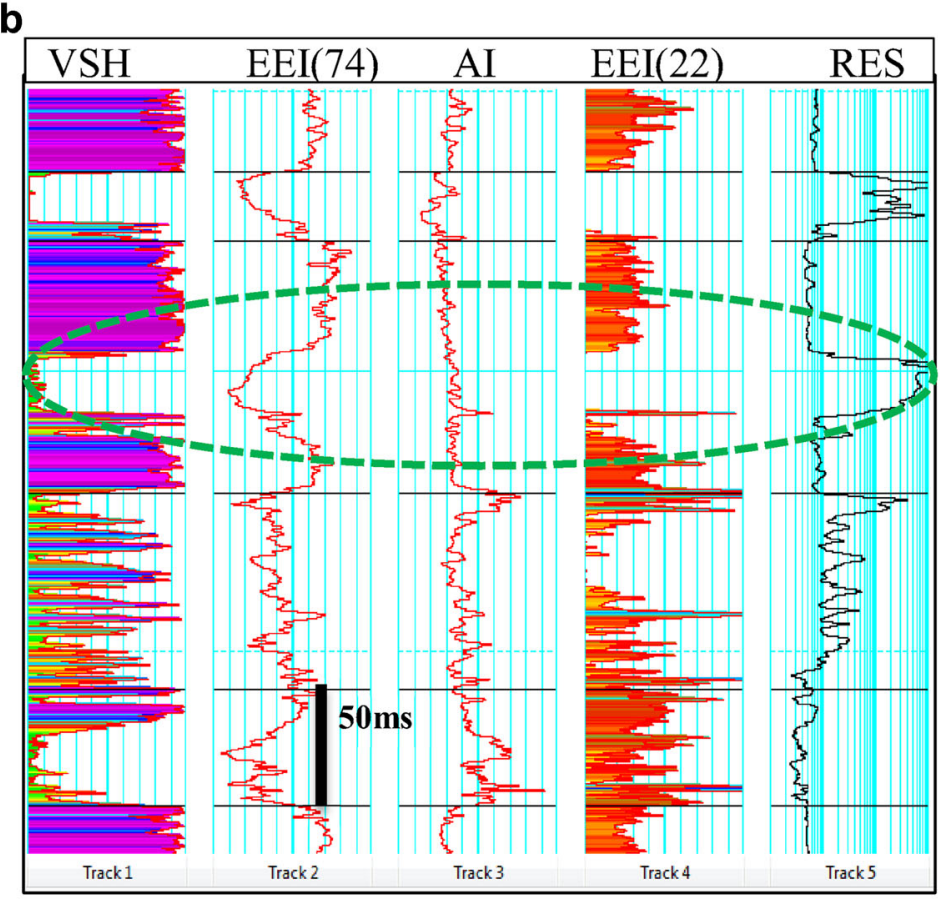

facies is more prominent at EEI (22) log. The yellow ellipse on Fig. 13a shows how good the anomaly is well defined when selecting the $\chi$ angle of $22^{\circ}$

high values of background EEI, corresponding to water sand, while the oil sand reservoirs are characterized by low values of background EEI.

Figure 15a shows the distribution of XB2 oil sheet sand body in section view, which is clearly reproduced on the basis of EEI $\left(22^{\circ}\right)$. The top and bottom of the sheet sand are 
Fig. 14 A section passing though wells showing extended elastic impedance at $\chi=22^{\circ}$ corresponding to the background EEI

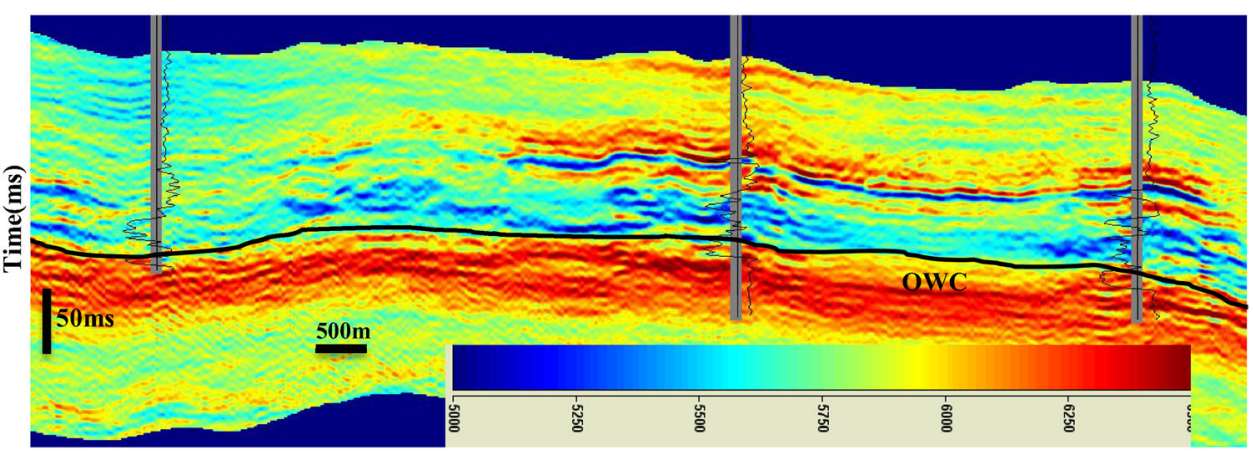

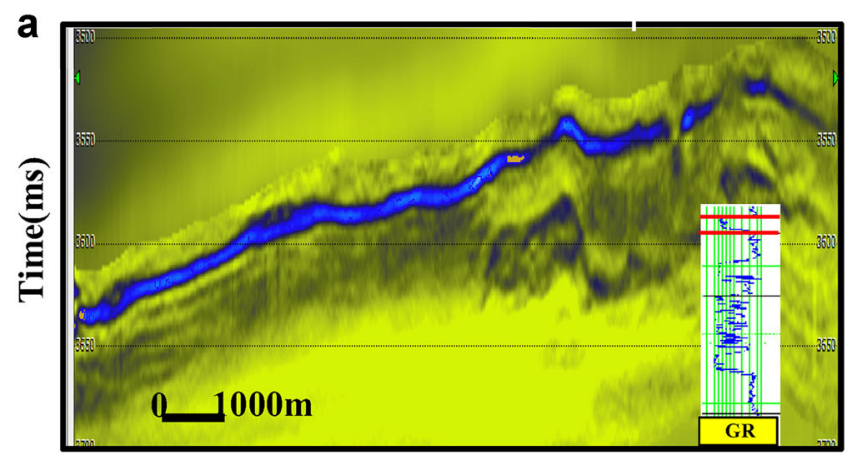

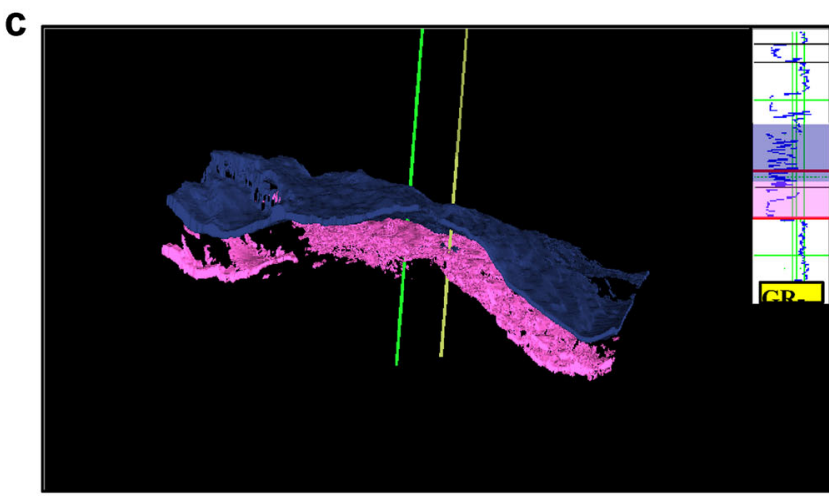

Fig. 15 a XB2 sheet sand body distribution clearly reproduced on the basis of EEI $\left(22^{\circ}\right)$ while GR $\log$ on the figure shows the top and bottom of the sheet sand. b View of the sheet sand body in 3D space.

shown, respectively, by two horizontal lines on GR log. Figure $15 \mathrm{~b}$ is the $3 \mathrm{D}$ view of the sheet sand where contour lines are also displayed, and it can clearly be seen that the sheet sand body conforms to the structure. Figure $15 \mathrm{c}$ shows the 3D distribution of lower reservoir sand bodies, as shown by blue and orange colors painted on GR log, captured using both porosity and shale volume cubes.

\section{Conclusion}

1. Extended elastic impedance (EEI) concept allowed us to characterize reservoir properties in the Nianga field through quantitative estimates of reservoir properties.

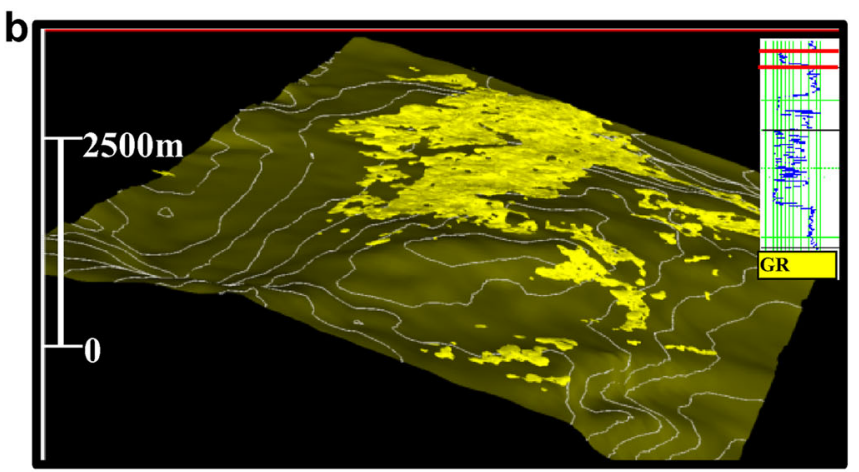

Contour lines are also displayed, and it can clearly be seen that the sheet sand body conforms to structure. $\mathbf{c}$ XB3pcf channel and sheet sand body distribution clearly reproduced

This was achieved by identifying the optimum EEI angle corresponding to each petrophysical property based on well $\log$ data. Three reservoir properties: porosity $(\phi)$, water saturation $(S w)$, and shale volume $(V$ sh) show high correlation with $\ln$ EEI $\operatorname{logs}$ at $\chi=57^{\circ}, 39^{\circ}$ and $74^{\circ}$, respectively.

2. In order to obtain the reservoir facies distribution, a background EEI was established based on an identified minimum energy angle, thereby enabling the mapping of reservoir facies from quantitative petrophysical properties and background EEI cubes.

3. This concept has proved to be more successful than conventional acoustic impedance approach especially with regard to fluid and lithology discrimination. 
Hence, it can be applied for the purpose of mapping favorable zones that may suggest possible future drilling locations.

4. The porosity and shale volume derived herein provided a superior description of reservoir sand. The EEI-based porosity agreed with the regional depositional trend of the Congo basin and provide and enhanced lateral distribution of the geological facies.

Open Access This article is distributed under the terms of the Creative Commons Attribution 4.0 International License (http:// creativecommons.org/licenses/by/4.0/), which permits unrestricted use, distribution, and reproduction in any medium, provided you give appropriate credit to the original author(s) and the source, provide a link to the Creative Commons license, and indicate if changes were made.

\section{References}

Archie GE (1942) The electrical resistivity $\log$ as an aid in determining some reservoir characteristics. Trans Am Inst Mech Eng 146:54-62

Avseth P, Mukerjo T, Mavko G (2005) Quantitative seismic interpretation-applying rock physics tools to reduce interpretation risk. Cambridge Press, ISBN 0-539-81601-7. Cambridge University Press

Avseth P, Veggeland T, Christiansen M, Ĺrdal KJ, Horn F (2013) Pseudo-elastic impedance calibrated to rock physics models for efficient lithology and fluid mapping from AVO data. In: Paper presented at the 75th EAGE conference \& exhibition incorporating SPE EUROPEC

Bachrach R (2006) Joint estimation of porosity and saturation using stochastic rock-physics modeling. Geophysics 71:53-63

Ball V, Blangy JP, Tenorio L (2013) Statistical aspects of rock property depth series: the trend is not your friend. In: Paper presented at the 83rd annual international meeting, SEG, expanded abstracts

Ball V, Blangy JP, Schiott C, Chaveste A (2014) Relative rock physics. Lead Edge 33:276-286. doi:http://dx.doi.org/10.1190/ tle33030276.1

Chatterjee R, Gupta SD, Farroqui MY (2013) Reservoir identificarion using full stack seismic inversion technique: a case study from Cambay basin oilfields, India. J Pet Sci Eng 109:87-95. doi:10. 1016/j.petrol.2013.08.006

Connolly P (1999) Elastic impedance. Lead Edge 18:438-452. doi:10. $1190 / 1.1438307$
Dong W (1996) A sensitive combination of AVO slope and intercept for hydrocarbon indication. In: Paper presented at the 58th conference and technical exhibition, Eur. Assn. Geosci. Eng, Paper M044

Doyen PM (2009) Porosity from Seismic data: a geostatistical approach. Geophysics 53:3963-3975

Dubucq DB, Van Riel S (2001) Turbidite reservoir characterization: multi-offset stack inversion for reservoir delineation and porosity estimation; a Gulf of Guinea example. In: Paper presented at the 71st annual international meeting, Soceity of Exploration geophysics

Hampson D, Russell B, Bankhead B (2005) Simultaneous inversion of pre-stack seismic data: SEG. Expand Abstr 24(1):1633-1637

Hicks G, Francis A (2006) Extended elastic impedance and its relation to AVO cross ploting and $\mathrm{Vp} / \mathrm{Vs}$. In: Paper presented at the EAGE extended abstract

Hodrick RJ, Prescott EC (1997) U. S. business cycles: an empirical investigation. J Money Credit Bank 29:1-16

Mavko G, Mukerji T, Dvorkin J (1998) The rock physics handbook: tools for seismic analysis in porous media. Cambridge University Press, Cambridge

Morteza Amiri JG-F, Golkar B, Hatampourd A (2015) Improving water saturation estimation in a tight shaley sandstone reservoir using artificial neural network optimized by imperialist competitive algorithm - a case study. J Pet Sci Eng 127:347-358. doi:10.1016/j.petrol.2015.01.013

Pauget F, Lacaze S, Valding T (2009) A global approach to seismic interpretation base on cost function and minimization. In: Paper presented at the 79th annual international meeting, SEG, Expanded abstracts

Romero CE, Carter JN (2001) Using genetic algorithms for reservoir characterisation. J Pet Sci Eng 31:113-123. doi:10.1016/S09204105(01)00124-3

Sams MS, Millar I, Satriawan W, Saussus D, Bhattacharyya S (2011) Integration of geology and geophysics through geostatistical inversion: a case study. First Break 29:47-56

Sengupta M, Bachrach R (2007) Uncertainty in seismic-based pay volume estimation: analysis using rock physics and Bayesian statistics. Lead Edge 26:184-189

Thomas M, Ball V, Blangy JP, Davids A (2013) Quantitative analysis aspects of the EEI correlation method. In: Paper presented at the $83^{\text {rd }}$ annual international meeting, SEG, Expanded abstracts

Vernik L, Fisher D, Bahret S (2002) Estimation of net-to-gross from P and S impedance in deepwater turbidites. Lead Edge 21:380-387

Whitecombe DA, Connolly PA, Reagan RL (2002) Extended elastic impedance for fluid and lithology prediction. Geophysics 67:63-67

Wiggins R, Kenny GS, McClure CD (1983) A method for determining and displaying the shear-velocity reflectivities of a geologic formation. European Patent Application 83300227.2, Bull. $84 / 30$, July 25 